\title{
Silting thickness analysis of regular desilting in rectangular and trapezoidal channel
}

\author{
Yang Wei ${ }^{1,2,3}$, Zhao Zhenbo ${ }^{1,2,3}$, Shi Yannan ${ }^{1,2,3}$ * \\ ${ }^{1}$ Zhejiang Guang Chuan Engineering Consulting Co., LTD, Zhejiang Hangzhou 310020, China; \\ ${ }^{2}$ Zhejiang Institute of Hydraulics \& Estuary, Zhejiang Hangzhou 310020, China; \\ ${ }^{3}$ Zhejiang Provincial Key Laboratory of Water Resources Disaster Prevention and Mitigation, Zhejiang Hangzhou 310020, China
}

\begin{abstract}
Silting in river is a dynamic process, so it needs to regular desilting. At present, underwater siltation monitoring is still in its early days and based on experience. This paper puts forward the criterion of discrimination, in which the flood discharge section is decreased by $20 \%$. It used the method of steady uniform flow in open rectangular and trapezoidal channel for calculation. The results show that reference values of dredging thickness in different section forms were determined. Siltation thicknesses of rectangular channel are linearly related to water depth. And the reduction rate of trapezoidal channel has a quadratic function relation with silting thicknesses. They were proportional to channel width and their rates trended to mitigation when the bottom width and flood depth were constant. In addition, the reference value of dredging thickness should be determined by combining with the bottom width, surface width, water depth and other actual situation.
\end{abstract}

\section{Introduction}

In order to meet the needs of modern social development, usually dredging is an effective method to restore river function of flood control, drainage, irrigation, water supply, navigation, and improve the water environment. Over the last few years, Zhejiang had dredged 350 million cubic meters by the five water management work, which included sewage treatment, flood control water, drainage water, water supply, focus on water conservation. The dredging work had been basically completed. But, sedimentation is a dynamic process because of the impacts of natural soil erosion, production and living, engineering construction, sewage discharge, rainfall, and so on ${ }^{[1-3]}$. With the further development of "Beautiful Rivers and Lakes", and better regular desilting mechanism ${ }^{[4]}$, the dredging will become a long-term and important ecological construction work.

At present, river regular desilting mechanism mainly stays in the siltation monitoring arrangement, fund preparation, organization management ${ }^{[4-6]}$, etc. However sedimentation monitoring is in the early stage. In addition, there is no requirement for regular desilting thickness, and it is based on experience, without reference. Medium and small rivers' management are particularly weaker. Rivers in Zhejiang Province are mainly medium or small, according to the water area survey data in 2005. The length of rivers below the county level is about $11.57 \mathrm{~km}$, accounting for about $84 \%$.

In practice, rivers' flood discharge capacity is in connection with factors such as breadth, depth, slope, bed roughness, bend and so on. In this paper, it was mainly considered the impact of different flood discharge section's siltation thickness, providing evidence for desilting work, so as to promote the standardized management of rivers and lakes.

\section{Research method}

\subsection{Standard of regular desilting thickness}

Regular desilting thickness refers to sedimentation thickness when rivers begin the next dredging. And sedimentation thickness is the difference in elevation between silt surface and bottom. The river with a designed section could calculate its sedimentation thickness according to the designed bottom elevation. While the river without design could calculate by third-party testing bottom elevation after desilting.

According to the regulations on the Cao 'e River, Wenruitang River and other large rivers, it should desilting in time, If the effective flood discharge section or water storage capacity is reduced by more than 20 percent. So this paper used the standard of effective flood discharge section's reduce rate of $20 \%$. It is shown in formula (1). And it also is the standard of regular desilting thickness.

$$
\mathrm{k}=\frac{A_{0}-A}{\mathrm{~A}_{0}} \times 100 \%
$$

Where $\mathrm{A}_{0}$ is the effective flood discharge section's area before deposition, $\mathrm{A}$ is the effective flood discharge section's area after deposition, $\mathrm{k}$ is the effective flood discharge section's reduce rate.

\footnotetext{
* Corresponding author: syn.0419@163.com
} 


\subsection{Computing method}

(1) channel form

A natural river tend to meander, and its channels are irregular. Its section shape, roughness coefficient and bottom slope are variations along the river. And its hydraulic factors are very complicated[7].

The general river section shape is mainly divided into rectangular channel, trapezoidal channel and compound channel. Small rivers are generally rectangular or trapezoidal channels. Therefore, this paper calculates according to trapezoidal or rectangular channel.

(2) computational formula
The effective flood discharge channel's area before and after deposition were calculated by formula (2) and (3). Bottom width and depth before and after deposition were calculated by formula (4) and (5).

$$
\begin{aligned}
& \mathrm{A}=(\mathrm{b}+\mathrm{mh}) \mathrm{h} \\
& A_{0}=\left(\mathrm{b}_{0}+\mathrm{mh}_{0}\right) \mathrm{h}_{0} \\
& \mathrm{~b}=2 \mathrm{mh}_{1}+b_{0} \\
& \mathrm{~h}=h_{0}-b_{1}
\end{aligned}
$$

Where $\mathrm{R}$ is hydraulic radius $(\mathrm{m}), \mathrm{m}$ is the slope coefficient, b0 is the bottom width before deposition (m), $\mathrm{b}$ is the bottom width after deposition (m), h0 is the depth before deposition (m), $\mathrm{h}$ is the depth after deposition (m), $\mathrm{h} 1$ is the desilting thickness (m).

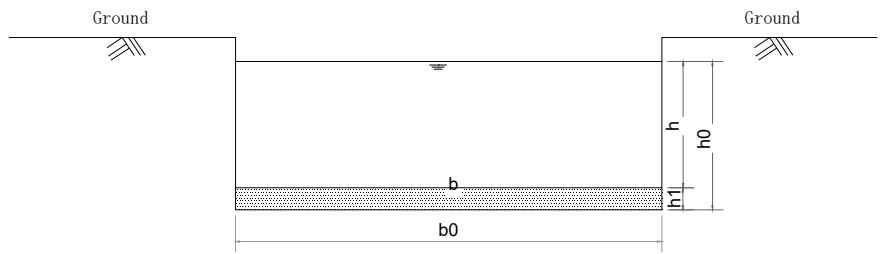

Figure. 1 rectangular channel

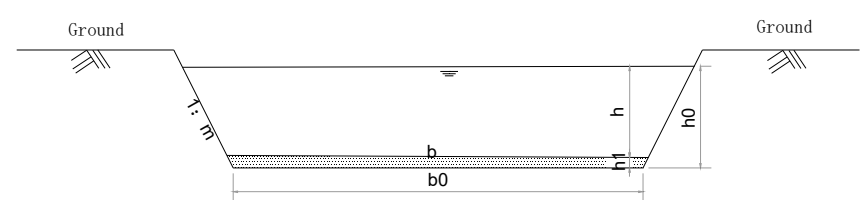

Figure. 2 trapezoidal channel

\section{Discussion and analysis}

According to formulas (1) to (5), the reduction ratio of section area is only related to the bottom width, siltation depth, slope coefficient and water depth of flood passage section. Thus we could get formula (6) after formula derivation.

$$
\mathrm{k}=\frac{\left(m h_{1}+b_{0}\right) h_{1}}{\left(m h_{0}+b_{0}\right) h_{0}} \times 100 \%
$$

\subsection{Analysis of rectangular section}

When the slope coefficient $m$ is 0 , the section of river is rectangular. So the effective flood discharge section's reduce rate $\mathrm{k}$ is only related to river depth and sedimentation thickness. See in particular formula(7).

$$
\mathrm{k}=\frac{h_{1}}{h_{0}} \times 100 \%
$$

As shown in the figure 3 , there is a linear relationship between the deposition thickness $\mathrm{H} 1$ and the depth $\mathrm{H} 0$ of the original flood discharge section. The greater the depth $\mathrm{h} 0$, the lower the slope $\mathrm{k}$. That is, the smaller the effect of siltation on the reduction of flood passage section is. Based on the actual situation, the depth of urban rivers is generally 2 to $3 \mathrm{~m}$. Therefore, standard of regular desilting thickness was recommended 50 to $60 \mathrm{~cm}$ when the flood discharge section of a river is reduced by $20 \%$.

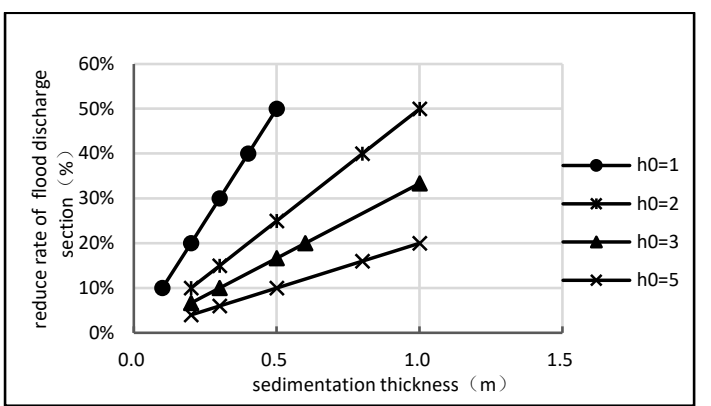

Figure. 3 Relation between reduction ratio of flood passage section and sedimentation thickness

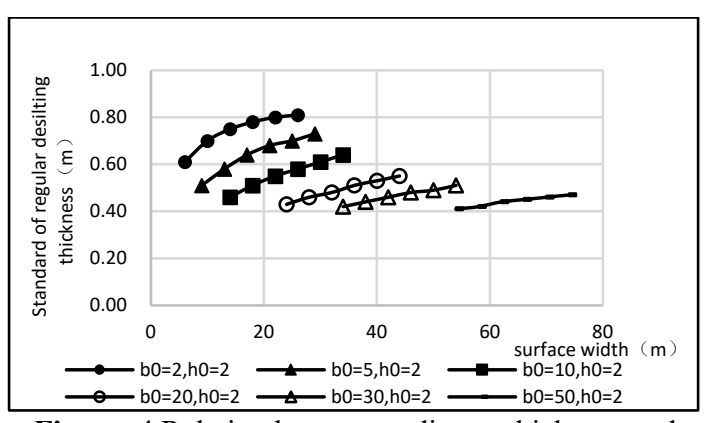

Figure. 4 Relation between sediment thickness and channel width when the flood discharge section is reduced by $20 \%(\mathrm{~h} 0=2 \mathrm{~m})$ 


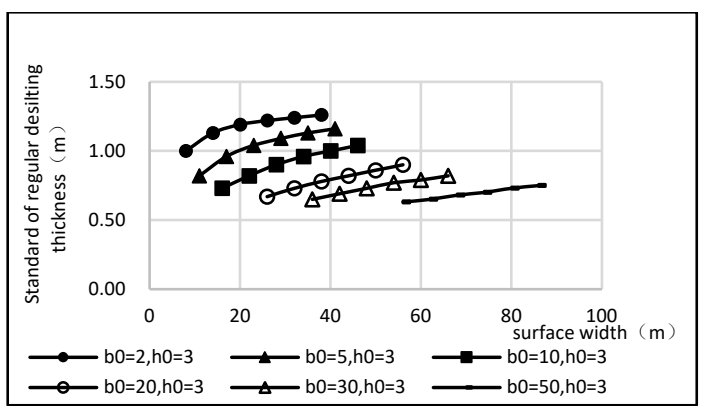

Figure. 5 Relation between sediment thickness and channel width when the flood discharge section is reduced by $20 \%(\mathrm{~h} 0=3 \mathrm{~m})$

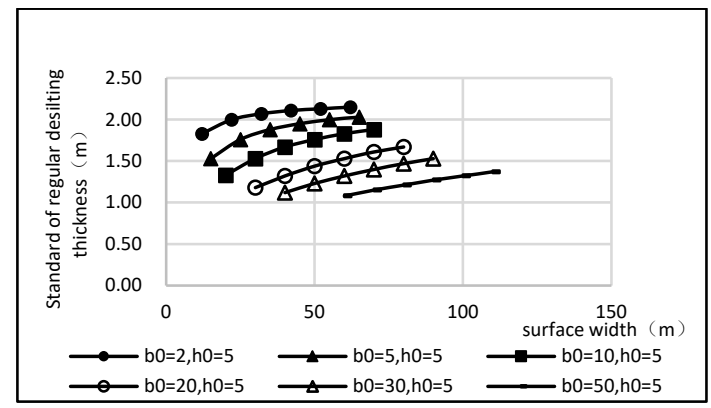

Figure. 6 Relation between sediment thickness and channel width when the flood discharge section is reduced by $20 \%$ $(\mathrm{h} 0=5 \mathrm{~m})$

\subsection{Analysis of trapezoidal section}

When the slope coefficient $m$ is not 0 , the section of river is trapezoidal. Because urban rivers' width is narrow, also their depth is shallow. Therefore, the following conditions were considered in this paper. For example, water depth h0 is 2 to $5 \mathrm{~m}$, the width is 2 to $50 \mathrm{~m}$, and the slope coefficient $\mathrm{m}$ is 1 to 6 . The calculation results are shown in Figure 4 to Figure 6.

Table 1 Standard of regular desilting thickness in different trapezoidal sections

\begin{tabular}{|c|c|c|c|c|c|c|}
\hline \multirow{3}{*}{$\begin{array}{l}\text { Bottom } \\
\text { width(m } \\
\quad)\end{array}$} & \multicolumn{6}{|c|}{ River depth (m) } \\
\hline & \multicolumn{2}{|r|}{$\mathrm{h}_{0}=2$} & \multicolumn{2}{|r|}{$\mathrm{h}_{0}=3$} & \multicolumn{2}{|r|}{$\mathrm{h}_{0}=5$} \\
\hline & $\begin{array}{c}\text { Surface } \\
\text { width }(\mathrm{m} \\
)\end{array}$ & $\begin{array}{l}\text { suggestive values of } \\
\text { regular desilting } \\
\text { thickness }(\mathrm{m})\end{array}$ & $\begin{array}{c}\text { Surface } \\
\text { width(m) }\end{array}$ & $\begin{array}{l}\text { suggestive values of } \\
\text { regular desilting } \\
\text { thickness }(\mathrm{m})\end{array}$ & $\begin{array}{c}\text { Surface } \\
\text { width }(\mathrm{m})\end{array}$ & $\begin{array}{l}\text { suggestive values of } \\
\text { regular desilting } \\
\text { thickness }(\mathrm{m})\end{array}$ \\
\hline \multirow[t]{2}{*}{$\mathrm{b}_{0}=2$} & $\leq 20$ & 0.7 & $\leq 20$ & 1.1 & 1 & 1 \\
\hline & $>20$ & 0.8 & $>20$ & 1.2 & $\geq 30$ & 2.1 \\
\hline \multirow[t]{2}{*}{$\mathrm{b}_{0}=5$} & $\leq 20$ & 0.6 & $\leq 20$ & 1.0 & / & / \\
\hline & $>20$ & 0.7 & $>20$ & 1.1 & $\geq 40$ & 2.0 \\
\hline \multirow[t]{2}{*}{$\mathrm{b}_{0}=10$} & $\leq 20$ & 0.5 & $\leq 20$ & 0.8 & / & / \\
\hline & $>20$ & 0.6 & $>20$ & 1.0 & $\geq 50$ & 1.8 \\
\hline \multirow[t]{2}{*}{$\mathrm{b}_{0}=20$} & $\leq 40$ & 0.5 & $\leq 40$ & 0.8 & $\leq 60$ & 1.5 \\
\hline & $>40$ & 0.6 & $>40$ & 0.9 & $>60$ & 1.7 \\
\hline \multirow[t]{2}{*}{$\mathrm{b}_{0}=30$} & / & 0.5 & $\leq 40$ & 0.7 & $\leq 60$ & 1.3 \\
\hline & l & l & $>40$ & 0.8 & $>60$ & 1.5 \\
\hline \multirow[t]{3}{*}{$\mathrm{b}_{0}=50$} & l & 0.5 & $\leq 70$ & 0.7 & $\leq 70$ & 1.1 \\
\hline & l & l & $>70$ & 0.8 & $70 \sim 100$ & 1.3 \\
\hline & l & / & l & l & $>100$ & 1.4 \\
\hline
\end{tabular}

Formula (6) can be simplified as formula (8).

$\mathrm{k}=\mathrm{D} \cdot h_{1}^{2}+E \cdot h_{1}+G$

Where D, E and $\mathrm{G}$ are the calculated constant of $\mathrm{m}, \mathrm{h} 0$ and b0.

Therefore, the reduction ratio $\mathrm{K}$ of flood discharge section and the deposition thickness $\mathrm{H} 1$ form a quadratic function relationship. When $\mathrm{k}=20 \%$, it could get formula (9).

$$
\mathrm{h}_{1}=\frac{\sqrt{b_{0}^{2}+0.8 b_{0} h_{0}+0.8 m^{2} b_{0} h_{0}}-b_{0}}{2 m} \times 100 \%
$$

As you can see from table 1, when the bottom width and river depth are certain, as the river surface width increases, suggestive values of regular desilting thickness are bigger under the flood passage section is reduced by $20 \%$. In other words, the larger the slope coefficient is, the stronger the cross-section flow capacity is, and the less the influence of siltation on the flood discharge cross-section of the river is, and the river can bear more siltation. But the surface width exceeds a certain value, it will be sluggish increase. And this shows that increasing the width of the river has limited effect on increasing overflow capacity. For instance, when bottom width is $2 \mathrm{~m}$, the depth before deposition is $3 \mathrm{~m}$, the slope coefficient $\mathrm{m}$ is 1 to 6 , and the surface width is 8 to $38 \mathrm{~m}$, its suggestive values of regular desilting thickness is 1.00 to $1.26 \mathrm{~m}$. When the surface width is more than $20 \mathrm{~m}$, suggestive values of regular desilting thickness grow slowly. It also shows that the larger the width of the river is, the smaller the effect of siltation on flood discharge is.

Generally, when the bottom width and river depth are certain, suggestive values of regular desilting thickness is positively correlated with the surface width. The bottom width and water depth of flood discharge section should be considered when determining the standard of regular desilting thickness 


\section{Conclusion}

This paper considered the influence of river sedimentation with different widths and depths. It supposed that the river is straight, and used the method of steady uniform flow in open rectangular and trapezoidal channel for calculation.

The result shows that reference values of dredging thickness in different section forms were determined, and put forward the criterion of discrimination, which the flood discharge section is decreased by $20 \%$.

Siltation thicknesses of rectangular channel are linearly related to water depth. The larger the water depth $\mathrm{h} 0$ of the flood passage section is, the lower the slope $\mathrm{k}$ is. The rectangular channel's reference values of dredging thickness were $0.2 \mathrm{~h}_{0}$.

On the other hand, flood discharge section's reduction rate of trapezoidal channel are related silting thicknesses with a nonlinear function. They were proportional to channel width and their rates trended to mitigation when the bottom width and flood depth were constant. In addition, the reference value of dredging thickness should be determined by combining with the bottom width, surface width, water depth and other actual situation.

\section{Acknowledgements}

This work was financially supported by Zhejiang Province Science and Technology Agency Key Research and Development Project (2017C03008), Zhejiang Province Water Resources Department Science and Technology Planning Project(RA1903), Zhejiang Province Water Resources Department Science and Technology Planning Project(RB2021), Zhejiang Province Water Resources Department Science and Technology Planning Project(RC1906), Zhejiang Province Water Resources Department Science and Technology Planning Project(RB2027).

\section{References}

1. BEI Zhigang, LIU Jinging, LUO Jing, XU Jin. Study on sedimentation in river channel based on principal component regression analysis[J] . Yangtze River, 2011, 42 (24) : 25-28.

2. Sun Yuyue, $\mathrm{He} \mathrm{Lu}$. Sedimentation causes and countermeasures of East \& West Tiaoxi in city of Huzhou [J] . Zhejiang Hydrotechnics, 2015, 4: 18-20 .

3. Pan Renliang, Zhu Huifang . Mathematical simulation of dynamic systems in Yangtze Estuary,s north channel Sedimentation[J]. Resources and Environment in the Yangtze Basin, 1996, 5 (2) : 177-181

4. Bao Ling, Tu Chengjie, Shi Yannan, etc . Investigation report on wheel thinning mechanism of plain river network in Zhejiang Province[J] . Application and practice of local water conservancy technology, 2019, 29: 179-183 .
5. Ye Chaoxia, Su Yingying, Shen Yimin . Analysis of sedimentation Calculation and regular desilting mechanism in Jiaxing' $s$ rivers[J] . Zhejiang Hydrotechnics, 2012, 1: 66-68.

6. Lin Changning, Ye Kunhua . Implementation of river chief system and lakes management in Longwan District[J] . 2018 Annual Conference of Zhejiang Hydraulic Society, 2018, 226-230 .

7. Ji Changhui . Numerical computation and analysis of discharge capacity of compound channel[D] . Nan Jing: Nanjing Hydraulic Research Institute, 2005 . 